\title{
Study of medicolegal awareness and problems of practicing obstetricians and gynecologists
}

\author{
Hetalkumar kyada ${ }^{1}$, Jitendra S Rathod ${ }^{2 *}$ \\ ${ }^{1-2}$ Associate Professor, ${ }^{1-2}$ Dept. of Forensic Medicine, ${ }^{1}$ PDU Government Medical College Rajkot, ${ }^{2}$ M P Shah Medical College, Jamnagar, \\ Gujarat, India.
}

*Corresponding Author: Jitendra S Rathod

Email: hardiksweet@yahoo.com

\begin{abstract}
Introduction: In the Present study, it has been tried to assess the awareness regarding medico-legal issues those arising during medical procedure among obstetricians and gynecologists in Rajkot city of Gujarat. The present study will help to know the areas of weakness and will suggest necessary remedial measures in this regards.

Materials and Methods: The present study was conducted at P. D. U. Government Medical College and Hospital. Study sample included Government and Private Obstetricians and Gynecologists of Rajkot city. Total 80 opinions were collected personally from Obstetricians \& Gynecologists. Specially prepared standard questionnaire was given to them and their response was collected. The questions in questionnaire were related to promptness \& procedural awareness in sexual offence cases, awareness of laws, insight about causes of negligence and awareness regarding various medicolegal issues. Collected responses were statistically analyzed using Microsoft excel.

Results and Conclusions: Government hospital doctors are more aware about the medico-legal issues arising during medical practice than the private hospital doctors. Among them, male doctors are more aware than the female doctors. Male doctors are more experienced than female doctors in handling of MLC cases. Government hospital doctors are more aware about the PCPNDT act and other laws related to practice. Promptness of examination of sexual assault victim as well as knowledge of collection and preservation of evidence in such cases was observed more in government doctors than the private doctors. $32.50 \%$ practitioners know that they have to attend the MLC's as per merit of the case and $16.25 \%$ do not know about it. It was quite clear in this study that $47.50 \%$ practitioners have the insight of real causes of negligence and litigations, $16.25 \%$ are confuse, while $27.5 \%$ are not aware of the same.
\end{abstract}

Keywords: PCPNDT, MTP, Medico legal, Obstetrician, Gynecologists.

\section{Introduction}

No greater opportunity, no greater responsibility, no greater obligation can fall to the lot of a Human being then to become a Medical professional. In the care of suffering he / she need scientific knowledge, technical skill, human understanding and now in addition awareness about the relevant laws of the land. Doctors have several ethical, moral and legal obligations in the performance of their duties. It is very important therefore, that every doctor understands the nature of these obligations and then fulfills these obligations to the best of their ability. Further, all doctors should know about medico-legal cases, concerned procedure and relevant legal provisions. ${ }^{1}$

The obstetricians and gynecologists are one of the important specialties of medical faculty. Increase in life expectancy, decreasing number of female births and reduction in family size cast a significant quantum of accountability on these doctors. They are working day and night for the benefit of patients. They are also very helpful with the Mother and Child Health Program, Family Planning Mission, etc. of Government of India. The obstetricians and gynecologists are also helpful to society at large for their work for crime against woman, in the form of examination of victim of sexual abuse, the PCPNDT act, Maternal Mortality. In these cases they have to assist the Investigating agencies and also appear in courts for the deposition of facts of examination, to know about medicolegal cases, concerned procedure and relevant legal provisions. $^{2}$

\section{Materials and Methods}

The present study was conducted at P. D. U. Government Medical College and Hospital. Study sample was included Government and Private Obstetricians and Gynecologists of Rajkot city in which total 80 opinions were collected personally from Obstetricians \& Gynecologists.

These select group of obstetricians \& gynecologists working in private and government set-ups were chosen, specially prepared a standard questionnaire was given to them and their response was collected. The questions in questionnaire were related to promptness \& procedural awareness in sexual offence cases, awareness of laws, insight about causes of negligence and awareness regarding various medicolegal issues.

The written responses to the provided questionnaire were studied in detail and were classified according to the decided objectives. The particular response of the group of the professionals was studied and analyzed in relation to issue in question.

Finally various grouped responses were correlated with the nature of obstetrics practice, medico-legal requirements and expectations of law.

Following questionnaires were considered during the study:

Questionnaires about awareness regarding various MedicoLegal issues

1. Promptness in examination of victim sexual assault

2. Evidence preservation in rape cases

3. Procedure related to death certification in MLCs 
4. Awareness regarding knowledge of the laws related to obstetrics and gynaecology practice

5. Awareness regarding provisions of PCPNDT act

6. Real causes of the negligence complaints

7. Need of examining genuine MLCs

Answers regarding awareness response were divided in four categories:

1. Aware

2. Partly Aware

3. Not Aware

4. No Response

All the Data were compiled and analyzed in Microsoft Excel software.
Result of the present study was compared with similar studies done by other authors.

\section{Observation}

The present study was carried out on 80 Obstetricians and Gynecologists of Rajkot city cases with minimum age of 21 years and maximum age of 80 years. Out of total 80 , males were 35 and females were 45 . Out of 35 Male Obstetricians and Gynecologists, 7 were working in Government Hospitals and 28 were working in Private Hospitals. Out of 45 Female Obstetricians and Gynecologists, 11 were working in Government Hospitals and 34 were working in Private Hospitals.

Table1: Awareness regarding promptness in examination of victim of sexual assault

\begin{tabular}{|l|c|c|c|c|c|c|c|c|}
\hline & \multicolumn{9}{|c|}{ Awareness Response } \\
\cline { 2 - 8 } & \multicolumn{2}{|c|}{ Aware } & \multicolumn{2}{c|}{ Partly Aware } & \multicolumn{2}{c|}{ Not Aware } & \multicolumn{2}{c|}{ No Response } \\
\cline { 2 - 8 } & Male & Female & Male & Female & Male & Female & Male & Female \\
\hline Govt. Doctor & $7(8.75 \%)$ & $11(8.75 \%)$ & $0(0.0 \%)$ & $0(0.0 \%)$ & $0(0.0 \%)$ & $0(0.0 \%)$ & $0(0.0 \%)$ & $0(0.0 \%)$ \\
\hline Private Doctor & $6(7.5 \%)$ & $8(10.0 \%)$ & $9(11.25 \%)$ & $10(12.5 \%)$ & $9(11.25 \%)$ & $10(12.5 \%)$ & $4(5.0 \%)$ & $6(7.5 \%)$ \\
\hline
\end{tabular}

Above table shows that out of 80 Obstetricians and Gynecologists included in this study 32 (13 Males and 19 Females) were aware, 19 (9 Males and 10 Females) were partly aware, 19 (9 Males and 10 Females) were not aware and 10 (4 Males and 6 Females) did not respond for issue regarding promptness in examination of Victim of Sexual assault. All Government Doctors were aware about the issue. Out of all 62 Private Hospital Doctors (28 Males and 34 Females), only 14 (6 Males and 8 Females) were aware about the issue.

Table2: Awareness regarding evidence preservation in rape cases.

\begin{tabular}{|l|c|c|c|c|c|c|c|c|}
\hline \multirow{2}{*}{} & \multicolumn{9}{|c|}{ Awareness Response } \\
\cline { 2 - 8 } & \multicolumn{2}{|c|}{ Aware } & Partly Aware & \multicolumn{2}{c|}{ Not Aware } & \multicolumn{2}{c|}{ No Response } \\
\cline { 2 - 8 } & Male & Female & Male & Female & Male & Female & Male & Female \\
\hline Govt. Doctor & $7(8.75 \%)$ & $11(13.75 \%)$ & $0(0.0 \%)$ & $0(0.0 \%)$ & $0(0.0 \%)$ & $0(0.0 \%)$ & $0(0.0 \%)$ & $0(0.0 \%)$ \\
\hline Private Doctor & $4(5.0 \%)$ & $6(7.5 \%)$ & $9(11.25 \%)$ & $7(8.75 \%)$ & $11(13.75 \%)$ & $14(17.5 \%)$ & $4(5.0 \%)$ & $7(8.75 \%)$ \\
\hline
\end{tabular}

Above table shows that out of 80 Obstetricians and Gynecologists included in this study 28 (11 Males and 17 Females) were aware, 16 (9 Males and 7 Females) were partly aware, 25 (11 Males and 14 Females) were not aware and 11 (4 Males and 7 Females) did not respond for issue regarding evidence preservation in Rape cases. All Government Doctors were very well aware about the issue as they were routinely dealing with such type of cases. Out of all 62 Private Hospital Doctors, only 10 (4 Males and 6 Females) were aware about the issue, 16 (9 Males and 7 Females) were partly aware, 25 (11 Males and 14 Females) were not aware and 11 (4 Males and 7 Females) did not respond to the question regarding the issue. Males were more aware regarding the issue compare to the female.

Table 3: Awareness regarding procedure related to death certification in mlcs

\begin{tabular}{|c|c|c|c|c|c|c|c|c|}
\hline & \multicolumn{8}{|c|}{ Awareness Response } \\
\hline & \multicolumn{2}{|c|}{ Aware } & \multicolumn{2}{|c|}{ Partly Aware } & \multicolumn{2}{|c|}{ Not Aware } & \multicolumn{2}{|c|}{ No Response } \\
\hline & Male & Female & Male & Female & Male & Female & Male & Female \\
\hline Govt. Doctor & $6(7.5 \%)$ & $9(11.25 \%)$ & $1(1.25 \%)$ & $0(0.0 \%)$ & $0(0.0 \%)$ & $1(1.25 \%)$ & $0(0.0 \%)$ & $1(1.25 \%)$ \\
\hline Private Doctor & $4(5.0 \%)$ & $7(8.75 \%)$ & $7(8.75 \%)$ & $6(7.5 \%)$ & $12(15.0 \%)$ & $14(17.5 \%)$ & $5(6.25 \%)$ & $7(8.75 \%)$ \\
\hline
\end{tabular}

Above table shows that out of 80 Obstetricians and Gynecologists included in this study 26 (10 Males and 16 Females) were aware, 14 (8 Males and 6 Females) were partly aware, 27 (12 Males and 15 Females) were not aware and 13 (5 Males and 8 Females) did not respond for issue regarding procedure related to death certification in MLCs. Most of the Government Doctors were aware about the issue. Out of all 62 Private Hospital Doctors, only 11 (4 Males and 7 Females) were aware about the issue and 26 (12 Males and 14 Females) were not aware.

Table 4: Awareness regarding knowledge of the laws related to obstetrics and gynecology practice 


\begin{tabular}{|l|c|c|c|c|c|c|c|c|}
\hline & \multicolumn{2}{|c|}{ Aware } & \multicolumn{2}{c|}{ Partly Aware } & \multicolumn{2}{c|}{ Not Aware } & \multicolumn{2}{c|}{ No Response } \\
\cline { 2 - 8 } & Male & Female & Male & Female & Male & Female & Male & Female \\
\hline Govt. Doctor & $6(7.5 \%)$ & $8(10.0 \%)$ & $1(1.25 \%)$ & $1(1.25 \%)$ & $0(0.0 \%)$ & $1(1.25 \%)$ & $0(0.0 \%)$ & $1(1.25 \%)$ \\
\hline Private Doctor & $5(6.25 \%$ & $9(11.25 \%)$ & $9(11.25$ & $6(7.5 \%)$ & $13(16.2$ & $13(16.25 \%$ & $1(1.25 \%)$ & $6(7.5 \%)$ \\
\hline
\end{tabular}

Above table shows that out of 80 Obstetricians and Gynecologists included in this study 28 (11 Males and 17 Females) were aware, 16 (10 Males and 7 Females) were partly aware, 27 (13 Males and 14 Females) were not aware and 8 (1 Male and 7 Females) did not respond for issue regarding knowledge of the Laws related to Obstetrics and Gynecology practice. Most of the Government Doctors were aware about the issue. Out of all 62 Private Hospital Doctors, only 14 (5 Males and 9 Females) were aware about the issue and 26 (13 Males and 13 Females) were not aware.

Table 5: Awareness regarding the provisions of PCPNDT Act

\begin{tabular}{|c|c|c|c|c|c|c|c|c|}
\hline & \multicolumn{8}{|c|}{ Awareness Response } \\
\hline & \multicolumn{2}{|c|}{ Aware } & \multicolumn{2}{|c|}{ Partly Aware } & \multicolumn{2}{|c|}{ Not Aware } & \multicolumn{2}{|c|}{ No Response } \\
\hline & Male & Female & Male & Female & Male & Female & Male & Female \\
\hline Govt. Doctor & $7(8.75 \%)$ & $11(13.75 \%)$ & $0(0.0 \%)$ & $0(0.0 \%)$ & $0(0.0 \%)$ & $0(0.0 \%)$ & $0(0.0 \%)$ & $0(0.0 \%)$ \\
\hline Private Doctor & $11(13.75 \%)$ & $16(20.0 \%)$ & $9(11.25 \%)$ & $9(11.25 \%)$ & $8(10 \%)$ & $5(6.25 \%)$ & $0(0.0 \%)$ & $4(5.0 \%)$ \\
\hline
\end{tabular}

Above table shows that out of 80 Obstetricians and Gynecologists included in this study 43 (18 Males and 27 Females) were aware, 18 (9 Males and 9 Females) were partly aware, 13 (8 Males and 5 Females) were not aware and 4 Females did not respond for issue regarding provisions of PCPNDT act. All Government Doctors were aware about the issue.

Table 6: Awareness about need of examining genuine mlcs

\begin{tabular}{|c|c|c|c|c|c|c|c|c|}
\hline & \multicolumn{8}{|c|}{ Awareness Response } \\
\hline & \multicolumn{2}{|c|}{ Aware } & \multicolumn{2}{|c|}{ Partly Aware } & \multicolumn{2}{|c|}{ Not Aware } & \multicolumn{2}{|c|}{ No Response } \\
\hline & Male & Female & Male & Female & Male & Female & Male & Female \\
\hline Govt. Doctor & $5(6.25 \%)$ & $9(11.25 \%)$ & $1(1.25 \%)$ & $1(1.25 \%)$ & $0(0.0 \%)$ & $0(0.0 \%)$ & $1(1.25 \%)$ & $1(1.25 \%)$ \\
\hline Private Doctor & $10(12.5 \%)$ & $7(8.75 \%)$ & $6(7.5 \%)$ & $4(5.0 \%)$ & $7(8.75 \%)$ & $11(13.75 \%)$ & $5(6.25 \%)$ & $12(15.0 \%)$ \\
\hline
\end{tabular}

Above table shows that out of 80 Obstetricians and Gynecologists included in this study 31 (15 Males and 16 Females) were aware, 12 ( 7 Males and 5 Females) were partly aware, 18 ( 7 Males and 11 Females) were not aware and 19 (6 Males and 13 Females) did not respond for issue regarding awareness about need for examining genuine MLCs. Out of all Government Doctors, most of the doctors were aware about the issue.

Table 7: Average percentage for awareness response regarding various medicolegal issues

\begin{tabular}{|c|c|c|c|c|c|c|c|c|}
\hline & \multicolumn{8}{|c|}{ Awareness Response } \\
\hline & \multicolumn{2}{|c|}{ Aware } & \multicolumn{2}{|c|}{ Partly Aware } & \multicolumn{2}{|c|}{ Not Aware } & \multicolumn{2}{|c|}{ No Response } \\
\hline & Male & Female & Male & Female & Male & Female & Male & Female \\
\hline $\begin{array}{l}\text { Govt. } \\
\text { Doctor }\end{array}$ & $6.3(7.9 \%)$ & $9.4(11.75 \%)$ & $0.6(0.75 \%)$ & $0.4(0.5 \%)$ & $0(0.0 \%)$ & $0.6(0.75 \%)$ & $0.2(0.25 \%)$ & $0.6(0.75 \%)$ \\
\hline $\begin{array}{l}\text { Private } \\
\text { Doctor }\end{array}$ & $7.4(9.25 \%)$ & $9.4(11.75 \%)$ & $8(10.0 \%)$ & $6.6(8.25 \%)$ & $9.9(12.4 \%)$ & $11.1(13.9 \%)$ & $2.7(3.4 \%)$ & $6.9(8.6 \%)$ \\
\hline
\end{tabular}

Above table shows that Government Hospital Doctors were more aware than Private Hospital Doctors regarding various Medico-legal issues. Male doctors were more aware than the Female doctors. Male doctors had responded more compare to female doctors.

Table 8: Awareness regarding real causes of the negligence complaints

\begin{tabular}{|c|c|c|c|c|c|c|c|c|}
\hline & \multicolumn{8}{|c|}{ Awareness Response } \\
\hline & \multicolumn{2}{|c|}{ Aware } & \multicolumn{2}{|c|}{ Partly Aware } & \multicolumn{2}{|c|}{ Not Aware } & \multicolumn{2}{|c|}{ No Response } \\
\hline & Male & Female & Male & Female & Male & Female & Male & Female \\
\hline Govt. & $6(7.5 \%)$ & $7(8.75 \%)$ & $1(1.25 \%)$ & $1(1.25 \%)$ & $0(0.0 \%)$ & $2(2.5 \%)$ & $0(0.0 \%)$ & $1(1.25 \%)$ \\
\hline Private & $12(15.0 \%)$ & $13(16.25 \%)$ & $7(8.75 \%)$ & $4(5.0 \%)$ & $9(11.25 \%)$ & $11(13.75 \%)$ & $0(0.0 \%)$ & $6(7.5 \%)$ \\
\hline
\end{tabular}

Above table shows that out of 80 Obstetricians and Gynecologists included in this study 38 (18 Males and 20 Females) were aware, 13 (8 Males and 5 Females) were partly aware, 22 (9 Males and 13 Females) were not aware and 7 Females did not respond for issue regarding real causes of the negligence complaints. Most of the Government Doctors were aware about the 
issue. Out of all 62 Private Hospital Doctors, only 25 (12 Males and 13 Females were aware about the issue and 20 (9 Males and 11 Females) were not aware.

\section{Discussion}

Table 9: Comparison of present study with similar study done by other author on awareness regarding various medico-legal issues

\begin{tabular}{|c|c|c|c|c|}
\hline S. No. & Medico-Legal Issue & $\begin{array}{c}\text { Awareness } \\
\text { Response }\end{array}$ & $\begin{array}{l}\text { Nanadkar } \\
\text { SD et al. }{ }^{3} \\
\text { (Out of 79) }\end{array}$ & $\begin{array}{c}\text { Present } \\
\text { Study } \\
\text { (Out of 80) }\end{array}$ \\
\hline \multirow{4}{*}{1} & \multirow{4}{*}{$\begin{array}{l}\text { Promptness in examination of victim } \\
\text { of sexual assault }\end{array}$} & Aware & $27(34.18 \%)$ & $32(40.0 \%)$ \\
\hline & & Partly Aware & $21(26.58 \%)$ & $19(23.75 \%)$ \\
\hline & & Not Aware & $22(27.85 \%)$ & $19(23.75 \%)$ \\
\hline & & No Response & $9(11.39 \%)$ & $10(12.5 \%)$ \\
\hline \multirow{4}{*}{2} & \multirow{4}{*}{ Evidence preservation in Rape cases } & Aware & $29(36.71 \%)$ & $28(35.0 \%)$ \\
\hline & & Partly Aware & $15(18.98 \%)$ & $16(20.0 \%)$ \\
\hline & & Not Aware & $28(35.45 \%)$ & $25(31.25 \%)$ \\
\hline & & No Response & $7(8.86 \%)$ & $11(13.75 \%)$ \\
\hline \multirow{4}{*}{3} & \multirow{4}{*}{$\begin{array}{l}\text { Procedures related to death } \\
\text { certification in MLCs }\end{array}$} & Aware & $24(30.37 \%)$ & $26(32.5 \%)$ \\
\hline & & Partlv Aware & $15(18.98 \%)$ & $14(17.5 \%)$ \\
\hline & & Not Aware & $28(35.45 \%)$ & $27(33.75 \%)$ \\
\hline & & No Resnonse & $12(15.19 \%)$ & $13(16.25 \%)$ \\
\hline \multirow{4}{*}{4} & \multirow{4}{*}{$\begin{array}{l}\text { Awareness regarding knowledge of } \\
\text { the Laws related to Obstetrics and } \\
\text { Gynecology practice }\end{array}$} & Aware & $26(32.91 \%)$ & $28(35.0 \%)$ \\
\hline & & Partly Aware & $18(22.79 \%)$ & $17(21.25 \%)$ \\
\hline & & Not Aware & $26(32.91 \%)$ & $27(33.75 \%)$ \\
\hline & & No Response & $9(11.39 \%)$ & $8(10.0 \%)$ \\
\hline \multirow{4}{*}{5} & \multirow{4}{*}{$\begin{array}{l}\text { Awareness regarding provisions of } \\
\text { PCPNDT Act }\end{array}$} & Aware & $30(37.98 \%)$ & $45(56.25 \%)$ \\
\hline & & Partly Aware & $15(18.98 \%)$ & $18(22.5 \%)$ \\
\hline & & Not Aware & $24(30.40 \%)$ & $13(16.25)$ \\
\hline & & No Response & $10(12.64 \%)$ & $4(5.0 \%)$ \\
\hline \multirow{4}{*}{6} & \multirow{4}{*}{$\begin{array}{l}\text { Awareness regarding need of } \\
\text { examining genuine MLCs }\end{array}$} & Aware & $32(40.51 \%)$ & $31(38.75 \%)$ \\
\hline & & Partly Aware & $12(15.19 \%)$ & $12(15.0 \%)$ \\
\hline & & Not Aware & $18(22.78 \%)$ & $18(22.5 \%)$ \\
\hline & & No Response & $17(21.52 \%)$ & $19(23.75 \%)$ \\
\hline \multirow{8}{*}{7} & \multirow{4}{*}{$\begin{array}{l}\text { Real causes of the Negligence } \\
\text { complaints }\end{array}$} & Aware & $35(44.30 \%)$ & $38(47.5 \%)$ \\
\hline & & Partly Aware & $11(13.93 \%)$ & $13(16.25 \%)$ \\
\hline & & Not Aware & $26(32.91 \%)$ & $22(27.5 \%)$ \\
\hline & & No Response & $7(8.86 \%)$ & $7(8.75 \%)$ \\
\hline & \multirow{4}{*}{ Average Percentages } & Aware & $36.51 \%$ & $40.5 \%$ \\
\hline & & Partly Aware & $19.35 \%$ & $19.5 \%$ \\
\hline & & Not Aware & $31.11 \%$ & $27.0 \%$ \\
\hline & & No Response & $12.83 \%$ & $13.0 \%$ \\
\hline
\end{tabular}

Table-9 is showing the comparison of this study with the study by Nanadkar SD et al ${ }^{3}$. In Study, by Nanadkar SD et al. ${ }^{3}$ had sample size of 79 , while this study had sample size of 80. While comparing average percentages, it shows that awareness regarding various Medico-Legal issues is more in Present study $(40.5 \%)$ compare to Nanadkar et al. ${ }^{3}$ $(36.51 \%)$.

In present study Obstetrics and Gynecologists working in Government hospitals are more aware about the Medicolegal issues than the Private Hospital Doctors. This may be due to Government doctors have to deal with the Medicolegal work on day to day basis compare to Private Hospital
Doctors for whom the Medico-legal work is not as such frequent. Similarly Opinions about the Medico-Legal work related agencies are better among the Government Doctors than the Private Doctors.

It is a known fact that adverse outcomes to the patients in the course of healthcare management are frequent day by day and this is not without the danger of professional risk to this group of practitioners. These risks end to specific investigative procedures and complicated operations and other. Same is the story in relation to the medico-legal management of cases of violence against woman. It is interesting to note that the social, medical and legal 
requirements in both these situations are qualitatively almost similar. Medical science is advancing and law is encroaching in almost every area of medical practice. It also cannot be ignored that society deserves the right to nourish great expectations from the advances in modern medicine and legal provisions aimed at their welfare. In the present study $32.50 \%$ practitioners knew that they have to attend the MLC's as per merit of the case and $16.25 \%$ did not know it. The faculty of obstetrics and gynecology is one of the risk prone specialties. The varied and unpredictable nature of obstetrics practice and the increasing complexities of various gynecological procedures put these specialists in an inherent problematic zone of complaints and litigations similar situations arises when the dilemma is as to whether death in a MLC is to be certified or not. It was found in this study that $17.50 \%$ were confused about procedure of death certification \& $33.75 \%$ were not aware of it at all.

The list of risk prone professional duties cum acts in these professionals is quite exhaustive. In case of obstetricians the acts of omission range from antenatal care to post delivery procedures and the acts of commission range from unnecessary caesarean to misplacement of babies in the wards. The gynecologist's problems are also not much less than these. In these regard the acts of omission range from failure to obtain consent to failure to use aseptic techniques. Same is story for acts of commission. Here they range from operation resulting in sterility to the problems of pregnancy following tubectomy. There is tremendous rise in the cases of violence against woman in last few decades. In this category particularly important are the cases of sexual assault, marital torture and child abuse. In these cases in addition to the clinical competence law requires these professionals to be wise and well versed in understanding and implementing legal provisions. The study observations indicate that $12.5 \%$ practitioners were ignorant of procedure of examining rape cases.

Quality treatment, information, safety and redressal are the important rights of patients recognized by CPA. It was quite clear in this study that $47.50 \%$ practitioners had the insight of real causes of negligence, litigations while $16.25 \%$ were confused \& $27.5 \%$ were not aware of the same. In recent years the CPA 1986 has widened its scope mainly in relation to issues like vicarious liability and corporate negligence. The cases of prenatal diagnosis, abortion (MTP Act 1971 \& amended 2002) and assisted reproduction expose the Obstetricians \& Gynaecologist to great professional stress and controversies. These specialists need to understand the gravity of change in appreciation of these situations by law. Because previously sex determination was a professional misconduct but now the same is treated as criminal offence in prescribed cases. It was noticed that $33.75 \%$ practitioners were not aware of laws governing their practice however $56.25 \%$ of them knew about details of PCPNDT act.

\section{Conclusion}

From present study, it can be concluded that
1. Government Hospital Doctors are more aware (90\%) about the Medico-legal issues arises during medical practice than the Private Hospital Doctors (60-65\%).

2. Male Doctors are more aware (70-75\%) about the Medico-legal issues arises during medical practice than the Female Doctors (60-65\%).

3. Government Hospital Doctors are more aware (9598\%) about the MTP act, PCPNDT act, Promptness of examination of Sexual Assault victim and collection and preservation evidence in such cases than the Private Hospital Doctors (60-65\%).

4. $32.50 \%$ practitioners know that they have to attend the MLC's as per merit of the case and $16.25 \%$ do not know about it.

5. It was quite clear in this study that $47.50 \%$ practitioners have the insight of real causes of negligence and litigations, $16.25 \%$ are confused while $27.5 \%$ are not aware of the same.

6. Government Hospital Doctors had over all good experience $(60-65 \%)$ with Medico-legal work related agencies such as Police, Forensic Medicine, and Court or as a witness than Private Hospital Doctors.

7. Male doctors had good experience (55-60\%) than Female doctors. Female (35-40\%) responded less compare to males regarding their experience with Medico-legal work related agencies.

\section{Suggestions}

1. The medical ethics, acts related to medical practice should be emphasized in post- graduate curriculum and Examinations.

2. The periodical CME programs should be made compulsory for all practitioners in particular obstetricians and gynecologists.

3. Integrated re-orientation programs of obstetricians and gynecologists be arranged with related specialists of medico-legal, prosecution and forensic science faculties.

\section{Abbreviations}

MLC - Medicolegal Case

PCPNDT Act- Pre-conception and Pre-natal Diagnostic Techniques Act

CPA - Consumer Protection Act

MTP Act - Medical Termination of Pregnancy Act

\section{Source of funding: None.}

\section{Conflict of interest: None.}

\section{References}

1. Agarwal SS, Legal Medicine Manual. $1^{\text {st }}$ ed. New Delhi: Jaypee Brothers Medical Publishers (P) Ltd; 2008.45.

2. Lele RD. The Medical Profession and Law. $1^{\text {st }}$ ed. Indian Hospital Association, Bombay Chapter [by] Sajjan Sons, 1992.14 
3. Nanandkar SD, Chavan GS. Assessment of medico-legal awareness of practicing obstetricians and gynecologists. $J$ Indian Acad Forensic Med 2008; 30(3): 136-40.
How to cite this article: kyada $\mathrm{H}$, Rathod J, Study of medicolegal awareness and problems of practicing obstetricians and gynecologists, Indian $J$ Forensic Community Med 2019;6(4):244-9. 